\title{
BeaLib: A Beacon Enabled Smart Library System
}

\author{
Monica Laxman Uttarwar', Arun kumar², Peter H. J. Chong1 \\ ${ }^{1}$ Department of Electrical and Electronic Engineering, Auckland University of Technology, Auckland, New Zealand \\ ${ }^{2}$ School of Electrical and Computer Engineering, National University of Singapore, Singapore City, Singapore \\ Email:gqk9695@aut.an.nz, elearun@nus.edu.sg, peter.chong@aut.ac.nz
}

How to cite this paper: Uttarwar, M.L., kumar, A. and Chong, P.H.J. (2017) BeaLib: A Beacon Enabled Smart Library System. Wireless Sensor Network, 9, 302-310. https://doi.org/10.4236/wsn.2017.98017

Received: June 22, 2017

Accepted: August 19, 2017

Published: August 22, 2017

Copyright (๑) 2017 by authors and Scientific Research Publishing Inc. This work is licensed under the Creative Commons Attribution International License (CC BY 4.0).

http://creativecommons.org/licenses/by/4.0/

\begin{abstract}
Nowadays, Global Positioning Systems (GPS) receivers are used for outdoor navigation, which are the part of recent smartphones and tablet devices. However, GPS is not suitable for indoor navigations due to its signal limitations which are blocked by ceiling and walls. Indoor navigation can be achieved through a mobile phone using a recent technology that utilizes Bluetooth, namely beacons. Beacons are small transmitters, run on Bluetooth Low Energy (BLE) technology, used as a point of reference for mobile devices and they can detect a Bluetooth enabled device once it enters its transmission range. In this paper, we present BeaLib: a beacon assisted indoor navigation technique for smart libraries. The proposed indoor navigation technique can also be used for other applications such as offices, retails, airports, hospitality, and education. For experimentation, beacons are placed in a library and a Bluetooth enabled smartphone is used to install a digital library application (App) which communicates with the beacons. The result shows that when the smartphone comes in the range of a beacon, it shows the information related to the book on the smartphone screen.
\end{abstract}

\section{Keywords}

Bluetooth Low Energy, Beacons, Proximity Sensor, Indoor Navigation, Global Positioning System

\section{Introduction}

Recently, Bluetooth Low Energy (BLE) is gaining popularity as a convenient way of wireless communication due to its low power requirement and inexpensive characteristic compared with classic Bluetooth [1] [2]. Also, it does not limit the number of devices to be connected for information sharing. While Classic 
Bluetooth is used for short-range (personal area network) communication, BLE provides fast and efficient handling of countless devices for similar applications [3].

Beacons are small transmitters, run on BLE technology, used as a point of reference for mobile devices and they can detect a Bluetooth enabled device once it enters into its transmission range [4]. In this work, for experimentation purpose, a beacon is linked with a book in the library which provides the basic information of the book to a reader/library user without even picking up the book. The prerequisite is that the reader should have the digital library App downloaded and installed in the smartphone or tablet. A user who has a Bluetooth turned on in the smartphone will receive the book information from the beacon if he/she is in the range of the beacon.

A Smart App is developed to provide easy access to library users with a Bluetooth-enabled smartphone or tablet. A user is able to see the basic information of the book on the mobile screen. This helps a library user to get easy access to the books without picking up individual books and it does not require an internet connection. As compared to GPS which is used for outdoor navigation [5], the proposed work is used for indoor navigation in the library.

Mostly, beacons have been used in marketing purpose for promotional offers. This paper explores another application of beacon as in indoor navigation. This work objective also includes the development of an Android mobile App using Java. The Estimote Bluetooth beacons and Android phones are used for the experimentations. Figure 1 shows a typical Estimote Bluetooth beacon available in the market.

\section{Related Work}

Bluetooth beacons are proximity sensors with small button cell batteries. They look like hockey pucks and are usually covered with a plastic case. The beacons are used to broadcast advertising services and information for publicity and promotional message or events [6]. Beacons have transmitters which work on BLE technology and can be programmed using a message. In a library, a user will receive the information about a book issued to him/her, return dates, fines etc. in the smartphone App.

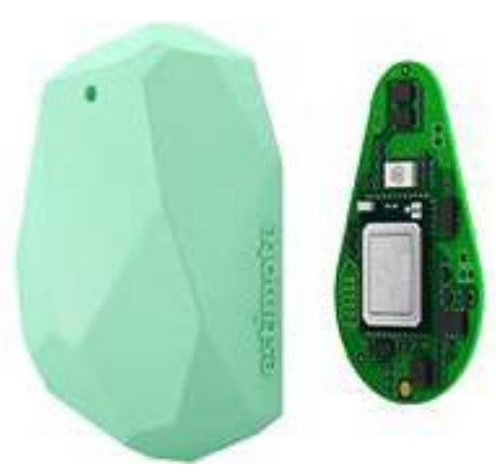

Figure 1. A typical Estimote bluetooth beacon. 
BLE is extensively used in health care applications where health sensors communicate biological readings and status to smartphones. Other healthcare applications built on BLE are monitoring systems of Electrocardiogram (ECG) [7], glucose [8], and blood pressure [9]. Few of the commercially available healthcare products are [10] [11]. BLE is a key enabler technology for The Internet of Things due to low power consumption and simple hardware implementation [12].

$\mathrm{BLE}$ is also used in hotels to inform the customers about the menu, prices and even the order can be placed using mobile App with the help of BLE and in that way, the customer does not have to wait for the waiter to come and take the order. This helps in cost cutting for expensive business. This also saves crucial time, for example, the waiter will take the orders and inform the chef and bring the food, by that time using the technology, and a customer can place the order and receive the ordered dishes. BLE can be used for jobs requiring accuracy like turning $\mathrm{ON}$ and OFF the lights and display on the different screen [13].

Magnetic beacons and receiver with magnetic sensors are attractive for a wide range of indoor events and applications, like pedestrian and robot navigation [14]. Mobile beacons in wireless sensor network (WSN) provide information of world-class applications like forest fire detection and animal tracking [15]. NFC is another contactless technology used for easy payment and paperless ticketing purpose [16]. NFC-enabled smartphone has helped to create a new application like mobile payment (m-payment) and mobile ticketing (m-ticketing). Authors in [17] have studied the contactless transport service using the SIM card as security element and NFC-enabled smartphone. The same application based on RFID is used in Auckland, New Zealand for bus, train and ferry ticketing which charges the users automatically once they reach their destination.

\section{Proposed Solution}

The aim of this work is to provide the indoor navigation to users in libraries like Auckland University of Technology library. In this paper, we present a beacon assisted indoor navigation technique for the smart library, BeaLib. A digital library App is created which displays the cover of the book, title, authors and a brief information about the book. Figure 2 shows an example of book information display on the Smart App.

The Estimote development kit is used for experimental purpose. The kit contains three Estimote beacons in different colours; lemon tart, candy floss and sweet beetroot. The beacons are enabled to broadcast not only Apple iBeacon packets but also Eddystone, an open beacon format from Google. The Estimote cloud can be used to manage the beacons. It allows the remote access to the settings of the beacons and location saved with Indoor Location SDK. There is information of the color, name, Identifier, and location of each of the beacon. It will display the information of the sticker beacon that is called as the "Nearables". It also provides the information of the applications that can be created using the "Apps" option. It also provides the information of the digital library App created as shown in Figure 3. 


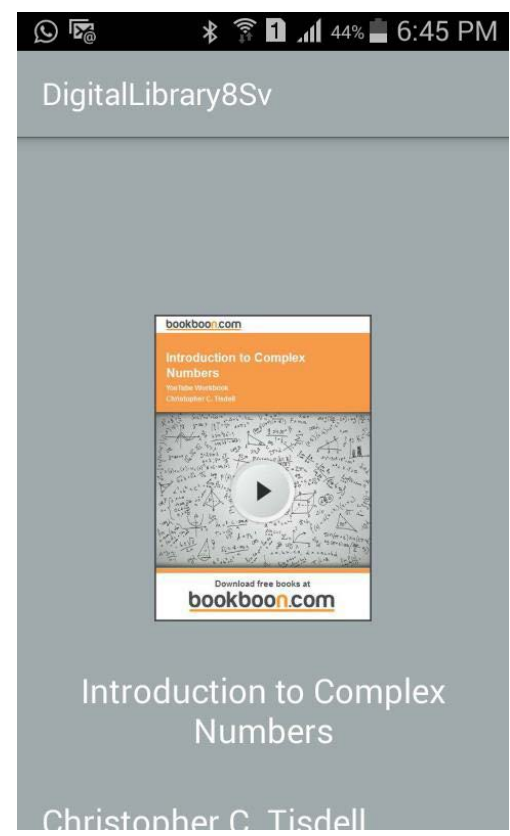

(a)

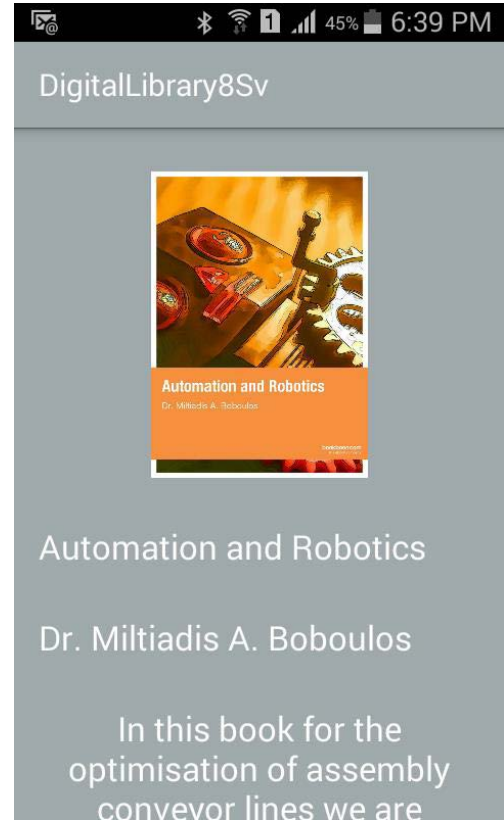

(b)

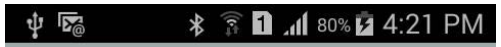

DigitalLibrary8Sv

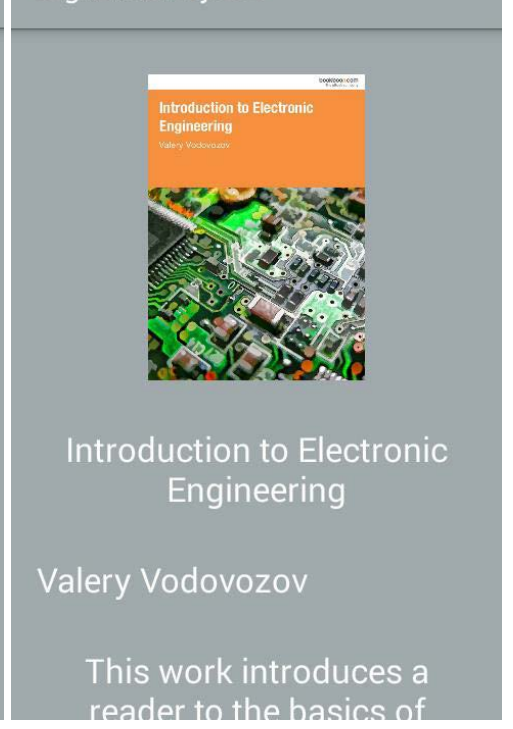

(c)

Figure 2. Book information [18].

It provides the information of the location and analytics like the number of visitors in particular time of the day and the location. The third floor of the Auckland University of Technology Library is chosen to test the BeaLib as it is a huge area full of books where Indoor navigation is difficult. It is also chosen to test the working of BeaLib in crowded areas as the signals of beacons get interfered and absorbed [20]. Figure 4 shows the block diagram of university library. The beacons are placed 10 to 20 meters apart in the library. Using BeaLib, the students and Staff members are able to find the books easily. The proposed 


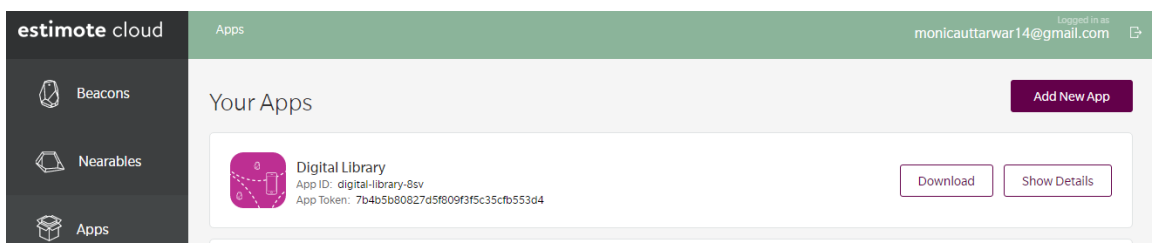

Figure 3. Created application [19].

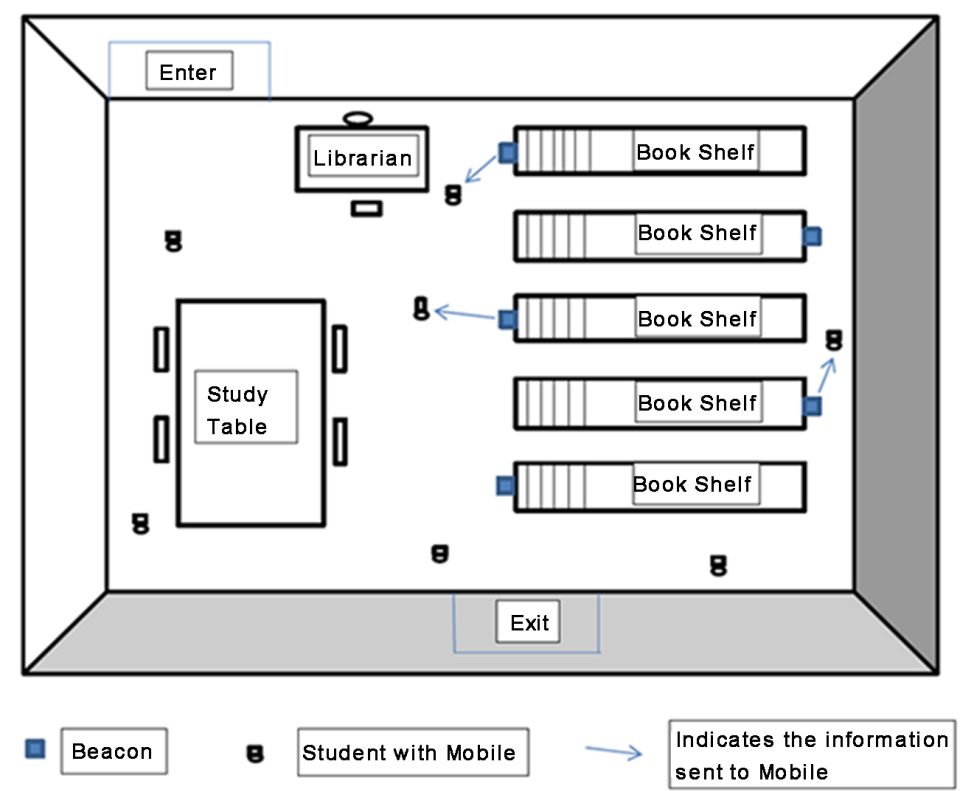

Figure 4. System structure block diagram of university library.

solution is usually tested by the students of Auckland University of Technology. Three beacons are placed near the books as shown in Table 1. When a user reaches in the range of a particular beacon the information related to the book will appear on the smartphone.

The flowchart of the BeaLib App is shown in Figure 5. First, the user needs to install the digital library application. Then the beacons check whether the Bluetooth is on or off. If the Bluetooth is on then the student will receive the information of the book depending on where the student is. If the student is near Lemon color beacon then the smartphone will display Introduction to Complex Numbers and if the student is near the Candy colour beacon then it will display the basic information of the Automation and Robotics book. If the student is near the Beetroot colour beacon then it will display the basic information of Introduction to Electronic Engineering. If the student is not near any of the beacons then it will display the image not available. Table 2 lists the features of Estimote beacons.

After that, if the user walks to another beacon then it will display the information of the book related to that beacon or it will just show no image available. If the user decides to leave the library or does not want any further information of the book then he/she can switch OFF the Bluetooth. In this way, the user can search the books without using the internet. 
Table 1. Beacon and related book information.

\begin{tabular}{cc}
\hline Beacon & Title of the Book \\
\hline Lemon & Introduction to Complex Number [21] \\
Candy & Automation and Robotics [22] \\
Beetroot & Introduction to Electronic Engineering $[18]$ \\
\hline
\end{tabular}

Table 2. Features of Estimote beacons [23].

\begin{tabular}{cc}
\hline Properties & Specification \\
Battery Life & 5 Years \\
Range & 200 Meters \\
Thickness & $24 \mathrm{~mm}$ \\
Built in Sensors & $\begin{array}{c}\text { Motion, Temperature, Ambient Light, } \\
\text { Magnetometer and Pressure Sensor }\end{array}$ \\
\hline
\end{tabular}

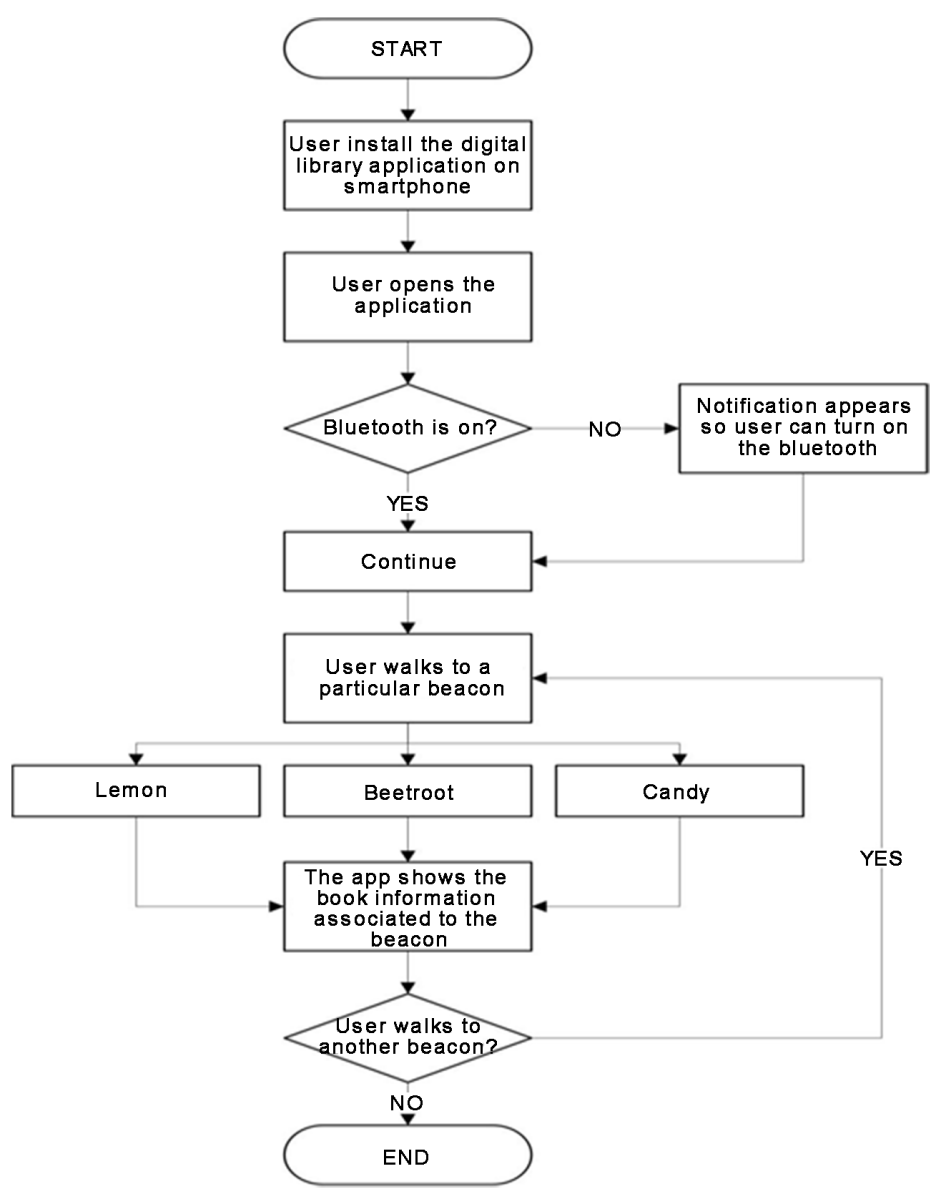

Figure 5. Flowchart of the digital library application.

\section{Discussion}

Once the Estimote beacons are linked to the Estimote account they can be programmed as per the required objective. An Android phone is required to run the 


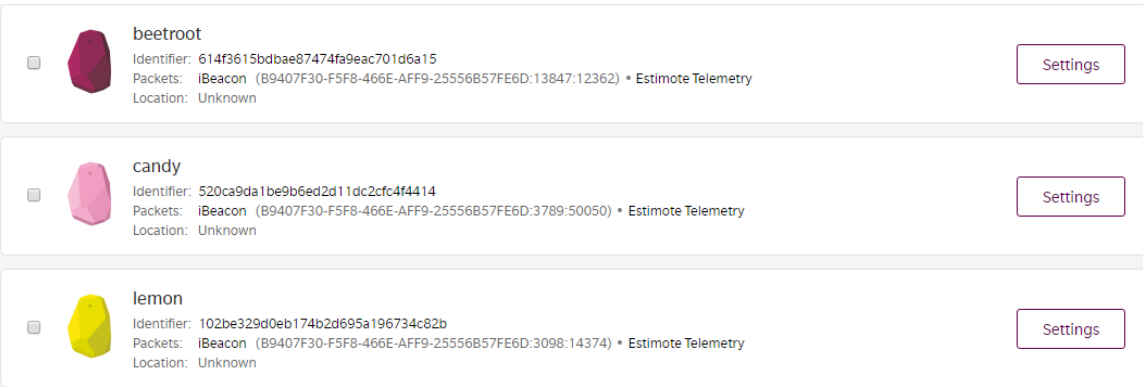

Figure 6. Beacon ID on the Estimote cloud [20].

Smart App and location of the beacons can be chosen as per the requirement of the project.

To run the Android App in a personal computer, Microsoft Windows or later version, Mac OS X 10.5.8 or later version with the Intel chip or Linux including GNU C Library 2.7 or later [24] is required. The Android Programming requires tools which are downloaded without any charges. The software required are Java JDK5 or later version, Android SDK, Java Runtime Environment (JRE) 6, Android Studio, Eclipse IDE for Java Developers and Android Development Tools (ADT) Eclipse Plug-in.

Each Estimote beacon has separate ID that can be changed, it is iBeacon format having three values that are UUID and Major ID and Minor ID as shown above (Figure 6) the beacon we have used in the project have the following. These IDs are identified by the mobile application and it makes them behave the way they show the output. The UUID is fixed and we can change the values of Major ID and Minor ID as per the requirement of the project.

The coding is used to give information about the Beacons and the ID. In the coding, the variables like title, author and a brief introduction of the book are declared using String Text and it uses variable name as "title", "author" and "intro". The image of the book is also stored and the background colour is stored. More variables can be introduced as per the requirement of the project.

\section{Conclusion}

This paper presented BeaLib: A Beacon Enabled Smart Library System. It is shown that Indoor navigation can be achieved through a mobile phone using a recent technology that utilizes Bluetooth, namely beacons. The proposed indoor navigation technique is for a smart library. BeaLib utilizes the Bluetooth Low Energy (BLE) technology. The proposed indoor navigation technique can also be used in other applications such as offices, retails, airports, hospitality, and universities. For experimentation, beacons were placed in a library and a Bluetooth enabled smartphone is used to install a digital library App which communicates with the beacons. The result shows that when the smartphone comes in the range of a beacon, it shows the information related to the book on the smartphone screen. 


\section{Acknowledgements}

This work was done in the Department of Electrical and Electronic Engineering, Auckland University of Technology, New Zealand. The experimentation was performed in the library of the Auckland University of Technology.

\section{References}

[1] Kalaa, M.O.A., et al. (2016) Evaluating Bluetooth Low Energy in Realistic Wireless Environments. IEEE Wireless Communications and Networking Conference (WCNC 2016), Doha, 3-6 April 2016, 1-6. https://doi.org/10.1109/WCNC.2016.7564809

[2] Ferro, E. and Potorti, F. (2005) Bluetooth and Wi-Fi Wireless Protocols: A Survey and a Comparison. IEEE Wireless Communications, 12, 12-26. https://doi.org/10.1109/MWC.2005.1404569

[3] Cepheus, C.S.R. (2015) Mobile Application for Localisation Using Bluetooth. EEE Student Reports, Nanyang Technological University, Nanyang, 38.

[4] Montanari, A., et al. (2017) A Study of Bluetooth Low Energy Performance for Human Proximity Detection in the Workplace. 2017 IEEE International Conference on Pervasive Computing and Communications (PerCom), Kona, 13-17 March 2017, 90-99.

[5] Kumar, A., et al. (2017) Location-Based Routing Protocols for Wireless Sensor Networks: A Survey. Wireless Sensor Network, 9, 25-72. https://doi.org/10.4236/wsn.2017.91003

[6] Kathy, D. (2016) Bluetooth Beacons Are Starting to Shine in Libraries: When a Beacon Recognizes an Equipped Smartphone, It Pings out Its Message. Computers in Libraries, 36.

https://www.questia.com/magazine/1G1-451633160/bluetooth-beacons-are-starting -to-shine-in-libraries

[7] Zhou, B., et al. (2013) A Bluetooth Low Energy Approach for Monitoring Electrocardiography and Respiration. 2013 IEEE 15th International Conference on e-Health Networking, Applications and Services (Healthcom 2013), Lisbon, 9-12 October 2013, 130-134. https://doi.org/10.1109/HealthCom.2013.6720653

[8] Ali, M., Albasha, L. and Al-Nashash, H. (2011) A Bluetooth Low Energy Implantable Glucose Monitoring System. 41 st European Microwave Conference (EuMC), Manchester, 12-13 October 2011, 1265-1268.

[9] Lin, Z.M., et al. (2014) Bluetooth Low Energy (BLE) Based Blood Pressure Monitoring System. International Conference on Intelligent Green Building and Smart Grid(IGBSG 2014), Taipei, 23-25 April 2014, 1-4.

[10] Fitbit Website http://www.fitbit.com/

[11] iBeacon for Developers-Apple Developer. https://developer.apple.com/ibeacon/

[12] Bluetooth Smart-Bluetooth Technology Website. http://www.bluetooth.com/Pages/Bluetooth-Smart.aspx

[13] Cho, H., et al. (2015) Measuring a Distance between Things with Improved Accuracy. Procedia Computer Science, 52, 1083-1088.

[14] Sheinker, A., et al. (2016) A Method for Indoor Navigation Based on Magnetic Beacons using Smartphones and Tablets. Measurement, 81, 197-209.

[15] Jebachristy, A., et al. (2016) Dynamic Improved Path Planning for Mobile Beacon in Wireless Sensor Network. Procedia Computer Science, 92, 385-388. 
[16] Mulliner, C. (2009) Vulnerability Analysis and Attacks on NFC-Enabled Mobile Phones. ARES.

[17] Arfaoui, G., et al. (2013) A Privacy-Preserving Contactless Transport Service for NFC Smartphones. In: International Conference on Mobile Computing, Applications, and Services, Springer, Berlin.

[18] Vodovozov, V. (2010) Introduction to Electronic Engineering. Ventus Publishing ApS.

[19] Kostka, J.K.a.Ł. (2012) Estimote. http://developer.estimote.com/

[20] Kostka, J.K.a.Ł. (2012) Estimote Beacons. https://community.estimote.com/hc/en-us/articles/200868188-How-do-I-modify-U UID-major-and-minor-values-

[21] Christopher, C. and Tisdell, C. (2015) Introduction to Complex Numbers. Christopher C. Tisdell \& bookboon.

[22] Boboulos, D.M.A. (2010) Automation and Robotics. Ventus Publishing.

[23] Kostka, J.K.a.Ł. (2012) Estimote Create Magical Experiences in the Physical World. http://estimote.com/?gclid=CL3UvZzy988CFQF_vQodtYEI6Q

[24] Mohtashim. Tutorial Point Simply Easy Learning. https://www.tutorialpoint.com/android/index.htm

Submit or recommend next manuscript to SCIRP and we will provide best service for you:

Accepting pre-submission inquiries through Email, Facebook, LinkedIn, Twitter, etc. A wide selection of journals (inclusive of 9 subjects, more than 200 journals)

Providing 24-hour high-quality service

User-friendly online submission system

Fair and swift peer-review system

Efficient typesetting and proofreading procedure

Display of the result of downloads and visits, as well as the number of cited articles

Maximum dissemination of your research work

Submit your manuscript at: http://papersubmission.scirp.org/

Or contactwsn@scirp.org 